Expatriate Adjustment and Effectiveness: The Mediating Role of Managerial Practices

\author{
Jeffrey P. Shay \\ Washington \& Lee University
}

J. Bruce Tracey*

Cornell University

Journal of International Management 15 (2009) 401-412

$\underline{\text { Author Note }}$

Jeffrey P. Shay, Williams School of Commerce, Economics, and Politics, Washington \& Lee University, Lexington VA 24459. e-mail: shayj@wlu.edu; phone: (406) 243- 5880; fax: (406) 243-2086.

J. Bruce Tracey, School of Hotel Administration, Cornell University, Ithaca, NY 14853. e-mail: jbt6@cornell.edu; phone: (607) 255-4179; fax number: (607) 255-4179.

* corresponding author 


\begin{abstract}
The purpose of this study was to examine the mediating effects of relations-oriented managerial behaviors on the relationship between two modes of expatriate adjustment-role innovation and personal change-and contextual performance. Using data from 194 expatriates and 505 of their subordinates, we found evidence of full mediation for the role innovationperformance relationship. For ratings of expatriate effectiveness, recognizing and team building behaviors appear to fully mediate the role innovation-performance relationship. For ratings of supervisor satisfaction, inspiring, supporting, and team building appear to fully mediate the role innovation-performance relationship. No significant results were found for the personal change-performance relationship. The results provide insights for extending current models of the expatriate adjustment process, and understanding the means by which expatriates fulfill their responsibilities.
\end{abstract}

Keywords: Expatriate adjustment Expatriate effectiveness Managerial practices 


\section{Expatriate Adjustment and Effectiveness: The Mediating Role of Managerial Practices}

\section{Introduction}

One of the ways that firms compete in international markets is by sending expatriates to establish and maintain overseas operations. One of the most important issues concerning expatriates is their adjustment to international assignments. Since Tung's (1981) seminal work, we have learned a great deal about the adjustment construct (e.g., Black et al., 1991) and the factors that may influence adjustment (e.g., Bhaskar-Shrinivas et al., 2005; Black and Gregersen, 1991; Kraimer et al., 2001; Liu and Shaffer, 2005; Takeuchi et al., 2005c). The majority of research in this domain focuses on the degree of expatriate adjustment, defined as the extent to which expatriates are psychologically comfortable along three dimensions of adjustment: work, interactions, and general culture (e.g., Black and Gregersen, 1991). While this research has generated a fairly comprehensive understanding about the various individual and contextual factors that may play a role in expatriate adjustment and the subsequent influence that expatriate adjustment has on important assignment outcomes, we argue that at least four gaps exist in the extant literature.

The first gap concerns the need to examine expatriate adjustment from alternative perspectives. Bhaskar-Shrinivas et al. (2005) meta-analysis found that approximately 10 to 15\% of the variance in expatriate performance was explained by expatriate adjustment. Based on these results, we submit that research examining expatriate adjustment from alternative perspectives may be helpful in explaining additional variance in expatriate performance. For example, rather than examining the degree of expatriate adjustment, an alternative perspective that has received some recent though limited attention is the adjustment process, and specifically, the modes of adjustment (i.e., personal and work-related changes) that may be utilized during the transition process (Shay and Baack, 2004). This is a critical issue, since the change efforts made by expatriates during the adjustment process may have a substantial impact on those with whom they work, and ultimately, their success. We argue that it may not be the degree to which an expatriate is adjusted but how the expatriate adjusts that influences important outcomes such as expatriate task and contextual performance. Thus, it is important to learn more about how expatriates adjust, and the implications for performance and effectiveness. 
The second gap concerns expatriate adjustment outcome measures. Many recent studies focus on expatriate turnover and turnover intentions as critical outcome variables (e.g., Takeuchi et al., 2005a,b) rather than more direct measures of expatriate effectiveness and performance, despite arguments that marginally effective or ineffective expatriates may do more harm to their organization by completing their assignment (e.g., Copeland and Griggs, 1985). We contend that it is equally if not more important to examine more proximal measures of expatriate effectiveness and performance.

The third gap centers on methodological concerns regarding the source of outcome data. Many studies rely on self-reported effectiveness ratings (e.g., Caligiuri, 1997; Parker and McEvoy, 1993) which introduce a number of problems, including leniency error (Meyer, 1980), restriction of range (Thornton, 1980), and halo error (Holzbach, 1978). In addition, other studies have utilized performance data gathered from supervisors (e.g., Takeuchi et al., 2005c) which introduces concerns regarding the rater's opportunity for regular and frequent observations of the expatriate's on-the-job behaviors. Thus, these and related measurement problems may pose threats to the interpretability and meaningfulness of the results.

The fourth gap concerns the expatriate adjustment-performance relationship. Recent studies have identified a number of distinct criteria that maybe used to assess expatriate performance and effectiveness (e.g., Caligiuri, 1997; 2000), and there is some evidence which links modes of adjustment to expatriate success (e.g., Shay and Baack, 2004). As such, careful consideration of performance measures is required, especially when examining alternative explanations of expatriate adjustment (i.e., degree of adjustment versus type or mode of adjustment). In addition, given the manner in which modes of adjustment have been defined and measured (e.g., Black, 1992; Nicholson, 1984; West et al., 1987), as well as evidence from the domestic and international leadership literatures (e.g., Yukl, 2002; House et al., 2004), it is likely that the adjustment-performance relationship is mediated by managerial behaviors that expatriates use to fulfill their role responsibilities. In particular, there may be several types of managerial behaviors, especially those associated with interpersonal relationships (i.e., the manner in which expatriates interact and work with local nationals), that may be relevant across many different cultural contexts and may further explain the links between expatriate adjustment and performance. Therefore, a rigorous examination of the modes of adjustment, behavioral practices that are demonstrated during the transition process, and key indices of expatriate performance, 
may add significant value to the growing literature on expatriate adjustment.

We will begin by presenting an overview of the research literature on expatriate adjustment. Then, we will discuss the literature on managerial practices and articulate a rationale for examining a set of relations-oriented behaviors that may mediate the relationship between expatriate modes of adjustment and ratings of performance. Finally, we will present the results from a study which lend support for our propositions, and discuss the implications for theory development and managerial practice.

\section{Expatriate adjustment}

There are two streams of research on expatriate adjustment. Most studies have focused on understanding the degree of psychological comfort with various aspects of the host culture (e.g., Black and Gregersen, 1991; Caligiuri, 1997; Gregersen and Black, 1990; Kraimer et al., 2001; Takeuchi et al., 2005c; Takeuchi et al., 2005b). Although studies on the degree of adjustment have provided important insights, as noted above, we argue that more research is warranted on the second stream of research, which focuses on modes of adjustment. This area of research is based primarily on Nicholson's (1984) work role transition theory (e.g., West, 1987; West et al., 1987; West and Rushton, 1989) and looks beyond the degree to which expatriates may be adjusted and examines how individuals may change in order to meet the role requirements of a new environment (e.g., Black, 1988,1992).

Nicholson's (1984) theory was based on socialization research (e.g., Van Mannen and Schein, 1979), which attempts to explain the processes by which individuals adjust to new organizational settings. Building on this research, Nicholson (1984) argued that work role transitions, defined as “... any change in employment status and any major change in job content” (p. 173), may have a substantial impact on an individual's professional development and performance. He posited that there are two general types of change processes that are associated with such transitions. The first is personal change, "which is absorbed through the person altering his or her frame of reference, values, or other identity-related attributes” (Nicholson, 1984, p. 175). The second type of change is role innovation in which an individual attempts to influence "role requirements so that they can better match his or her needs, abilities, and identity” (Nicholson, 1984, p. 175). That is, individuals may assume an internal orientation toward change (personal 
change), a more externally-focused approach (role innovation), make no changes, or invoke both internal and external changes.

Black (1992) conducted one of the first and perhaps only studies that confirmed the relationship between socialization and modes of adjustment within an international context. Black found that collective socialization tactics, which are manifested when all newcomers have a common set of experiences, were positively related to role innovation (Note: Black's study did not include the personal change mode of adjustment). However, contrary to propositions offered by Van Mannen and Schein (1979), two other types of socialization tactics (i.e., serial tactics, which utilize experienced employees as role models, and fixed tactics, which focuses on design and timing of the socialization sequence) were inversely related to role innovation. Black suggested that these latter findings may be due to differences between the expectations of new hires and expatriate managers regarding the appropriateness of role innovations.

A few other studies have examined the links between modes of adjustment and expatriate performance. Thomas et al. (Thomas and Ravlin, 1995; Thomas and Toyne, 1995) found a positive relationship between expatriate adaptation, a construct that appears to embody both personal change and role innovation, and subordinate ratings of managerial effectiveness. Part of the conceptual foundation for this study was based on attribution theory (e.g., Jones and Davis, 1965), which suggests that individuals make judgments about others based on the motives and intentions which are perceived as causes of people's behavior. Thus, expatriate managers may be viewed positively if they demonstrate efforts to adjust their values, attitudes, and behaviors to become aligned with those of the host culture. More definitive support for this conclusion was presented by Shay and Baack (2004), who found significant relationships between expatriate ratings of role innovation (Black's, 1992 measure) and self-reported ratings of performance.

However, despite initial evidence for the relationship between modes of adjustment and expatriate performance, the conceptualization and operationalization of personal changes and role innovation do not comprehensively capture the full range of behaviors that expatriates may use during the transitional process. That is, the process by which adjustment modes may influence performance is not fully specified. Nicholson (1984) argued that when individuals engage in personal change they alter their own attitudes and behaviors to fit the role requirements. Though the items in Nicholson's measure reflect changes in terms of one's values, attitudes, career goals, 
and personality, the items do not capture the specific managerial behaviors that may facilitate such changes. Similarly, Nicholson's operationalization of the role innovation construct (West et al., 1987) does not identify the specific managerial behaviors that may foster the personal change process. So while the work role transition theory may provide a general explanation of how an individual may change and make adjustments to his or her work roles, it does not encompass the specific behaviors that may be evident during the adjustment process and subsequently impact

performance and effectiveness. As such, in order to more fully explain how expatriates adjust to their new positions, it appears that consideration should be given to the managerial practices that may be manifest during the adjustment process.

\section{Mediating role of managerial practices}

For over 50 years, leaders and managers have been studied from a variety of perspectives. One of the first studies was conducted by Hemphill (1949), who suggested that effective leadership could be explained by two fundamental dimensions. The first dimension was consideration and is characterized by the degree of supportiveness and concern demonstrated by managers and leaders toward their subordinates. The second dimension was initiating structure, which was characterized by the degree to which managers and leaders focused on the task and job-related requirements of the workplace. Hemphill's research was extended by Katz et al. (e.g., Katz et al., 1950, 1951; Katz and Kahn, 1952) who derived a three-dimensional model that included task-oriented behaviors, relations-oriented behaviors, and participative leadership. Task-oriented behaviors included planning and scheduling work, coordinating subordinate efforts, and providing the necessary resource to complete the work. Relations- oriented behaviors included being supportive, considerate, and helpful with subordinates. Participative leadership included behaviors focused on making the group work as a unit, such as ensuring that employee engage in supportive and constructive discussions in meetings that are oriented toward problem solving.

Over the years, many hundreds of studies have examined the relationships between these general leadership dimensions and a variety of outcomes, particularly subordinate ratings of satisfaction with the leaders and leader effectiveness. However, the results have been weak and inconsistent. For example, some studies showed that subordinates were more satisfied with leaders who engaged in lesser degrees of initiating structure/task-oriented behavior, while in other studies 
subordinates were more satisfied with leaders who engaged in greater degrees of initiating structure/task-oriented behaviors (cf., Bass, 1990).

To address these mixed results, researchers have provided more detailed explanations of the behaviors utilized by managers and leaders (e.g., Mintzberg, 1973; Stogdill, 1974; House and Mitchell, 1974; Morse and Wagner, 1978; Luthans and Lockwood, 1984). These and other attempts to define and refine effective leadership behaviors have led to the development of several specific and narrowly-defined sets of behavioral dimensions that have been labeled as managerial practices. One of the most useful explanations was provided by Yukl (2002), who presented an integrative taxonomy that was based on research from a wide variety of studies that used both empirical and theoretical approaches for determining the content and range of effective managerial behaviors. Yukl's taxonomy currently includes 11 "middle-range behavior categories” that have been operationalized in a questionnaire called the Managerial Practices Survey (MPS) (Yukl, 1990). Yukl argued that this taxonomy represents most of the behaviors that are relevant for understanding managerial effectiveness. Results from an extensive validation effort support this taxonomy (Yukl et al., 1990). Across six separate studies, Yukl et al. found that planning, problem solving, clarifying, monitoring, and motivating behaviors had consistently high correlations with ratings of managerial effectiveness, and that each of the managerial practices was significantly related to performance and effectiveness outcomes in at least one of the studies.

Within the international leadership and management domain, there are two primary perspectives regarding the generalizability of managerial behaviors research across cultural contexts. Proponents of the contingency perspective argue that the specific attitudes, values, beliefs, and cultural norms which define and differentiate national cultures require that leaders utilize a distinct set of behaviors in order to be effective (Hofstede, 1980; Triandis, 1994). That is, the effectiveness of specific leader behaviors is contingent, in part, on the cultural context. And indeed, there is substantial evidence which substantiates this contention (e.g., Dorfman, 2004; House et al., 1997).

However, there is also evidence for a universal explanation, which posits that some types of leadership and managerial behaviors may be effective across many cultural contexts. One of the most comprehensive cross-cultural leadership studies was the recently completed Global Leadership and Organizational Behavior Effectiveness (GLOBE) Research Program (House et al., 
2004). One of the primary purposes of the GLOBE study was to determine the extent to which various leadership behaviors and attributes may be universally-accepted and effective across cultures. Based on data gathered from more than 17,000 middle- managers working in 951 organizations located in 62 different countries, House et al. found that two general leadership dimensions - charismatic/value-based leadership and team-oriented leadership-appear to be applicable in almost all types of cultural contexts. The results showed positive relationships between the major values that can be used to define national culture (e.g., collectivism, gender egalitarianism, uncertainty avoidance, etc.) and the efficacy of a wide range of visionary, inspirational, and performance-oriented behaviors, as well as collaborative, diplomatic and supportive behaviors. And while the GLOBE study also supported the contingency perspective (e.g., people in high power distance cultures are not as receptive to participative leadership as people in low power distance cultures), the findings demonstrate that many managerial and leadership behaviors appear to have broad relevance and utility.

The conceptualizations of charismatic/value-based and team-oriented leadership are quite consistent with many of the relations-oriented behaviors that are included in Yukl's (1990, 2002) managerial practices taxonomy. Yukl (2002) defined relations-oriented managerial behaviors as those that are "primarily concerned with improving relationships and helping people, increasing cooperation and teamwork, increasing subordinate satisfaction, and building identification with the organization” (p. 65). Example practices include inspiring, providing support and encouragement, recognizing contributions, and facilitating social interaction. These behaviors appear to be a direct reflection of the "inspirational” and "team integration” dimensions (among others) associated with charismatic/value-based and team-oriented leadership, respectively. Indeed, the GLOBE scholars acknowledged that these two general leadership dimensions are “closely related to prior leadership constructs found in the extant leadership literature” (Hanges and Dickson, 2004, p. 145).

Given the potential cultural generalizability of relations-oriented managerial practices and the accompanying need to account for the specific behaviors that expatriates may use during the adjustment process, we contend that the managerial practices which facilitate effective interpersonal relationships may provide an explanatory mechanism for linking modes of adjustment to measures of expatriate performance and effectiveness. Recall that Nicholson's (1984) work role transition theory is based on socialization research (e.g., Van Mannen and Schein, 
1979). One of the key learning areas involved in the socialization process pertains to work relationships and interpersonal skills (e.g., Chao et al., 1997). As such, an expatriate's performance and effectiveness may not only depend on the extent to which expatriates are oriented toward making personal changes and work role innovations, but also the degree to which they engage in behaviors that facilitate positive relations with those in their immediate work context.

In addition to linking expatriate modes of adjustment to the specific behaviors that may be used during the adjustment process, focused attention should also be given to the outcomes of expatriate behavior. Adjustment, in and of itself, is not the critical issue. Rather, it is the results of adjustment efforts that are most relevant. Thus, it is important to clearly identify the meaning and measurement of expatriate effectiveness.

\section{Expatriate effectiveness}

Research on expatriate effectiveness has been limited by the lack of a consistent definition and the manner in which the effectiveness construct has been measured (Shay and Baack, 2004). In fact, much of the adjustment research has confounded adjustment with effectiveness (cf., Hannigan, 1990). While an expatriate's orientation toward change and use of certain behaviors during the adjustment process may ultimately result in a variety of desired outcomes (e.g., local national perceptions of expatriate effectiveness), we argue that such behaviors are not directly indicative of how well an expatriate is fulfilling his or her responsibilities. Thus, it is necessary to consider more specific and direct measures of expatriate managerial performance and effectiveness.

As noted above, there have been some attempts to more clearly define the expatriate performance and effectiveness domain. One of the more rigorous efforts was conducted by Caligiuri (1997). Caligiuri developed and tested a taxonomy of expatriate "success" that distinguished three possible criteria for assessing expatriate performance: completion of the foreign assignment; cross-cultural adjustment while on assignment; and performance on the foreign assignment. The completion criterion was defined as the premature termination of, or return from, the scheduled assignment duration. Cross-cultural adjustment was defined in terms of the degree or extent of psychological comfort to the host country (e.g., Black and Gregersen, 1999; Note: adjustment mode was not considered in this particular study.). Performance during the 
foreign assignment was defined in terms of technical performance requirements, which focus on the completion of job-specific tasks, duties, and responsibilities, and contextual performance requirements, which focus on establishing, maintaining, and developing positive working relationships among employees.

Contrary to the proposition that each of these indices would be empirically orthogonal, the results from Caligiuri's (1997) study showed that the measures of desire to complete assignment and cross-cultural adjustment were significantly related (negatively). One interpretation of this finding was that these two criteria may be indices of a latent "cross-cultural affect or satisfaction" (Caligiuri, 1997, p. 131) construct. We concur-the extent to which expatriates are positively disposed to their assignment may be directly linked to their willingness to complete their assignment. In contrast, Caligiuri's results showed that the third success criterion, performance on the foreign assignment, was empirically distinct from the other proposed criteria (i.e., not significantly correlated with the completion and adjustment variables). This finding supports contentions that cross-cultural adjustment may be an antecedent of expatriate performance (e.g., Hannigan, 1990; Black, 1992). Thus, although many elements of success may be unique to a particular position or context in which one works (e.g., the same job may have different technical requirements or priorities in different contexts) technical and contextual performance measures may have substantial utility for gaining a more comprehensive understanding of expatriate effectiveness.

In addition to carefully considering the appropriate content domain, it is also important to select appropriate sources of performance ratings (i.e., supervisors, peers, subordinates, and/or self-reports). Although most organizations rely on supervisors as raters, there is evidence that these individuals might not always provide the most reliable and valid data. For example, Barrett's (1966) study concluded that supervisory evaluations depend heavily on how supervisors think the work is being done rather than how well it is actually be done. Latham and Wexley (1994) argued that the subjectivity and bias that are often inherent in supervisory evaluations are the result of the limited instances in which the supervisor actually sees the employee on the job. This is particularly salient for the evaluation of expatriate managers since raters are often corporate managers who are posted in the organization's home country headquarters (Gregersen et al., 1996) and therefore do not have the opportunity to make frequent observations of expatriate managers on the job. 
Given these concerns, one of the most valid sources of performance information may be an expatriate's subordinates. Subordinates have the opportunity to frequently observe the focal manager on the job. And while performance ratings offered by subordinates may be subject to various rating biases (e.g., attitudinal disposition of rater; leniency/harshness tendencies; stereotyping; status differences; etc.), these individuals are in a position to identify the extent to which particular behaviors are used and thus, judge the outcomes of the expatriate's behaviors. Much of the research on domestic leadership and managerial practices literature has utilized subordinate ratings of satisfaction with their manager/leader and ratings of performance and effectiveness as criteria for success (Yukl, 2002). By extension, and elaborating on Shay and Baack's (2004) findings, expatriate managers who engage in a role innovation mode of adjustment and demonstrate supporting behaviors (e.g., acceptance and positive regard for subordinates) may positively impact subordinates' perceptions of satisfaction with the focal manager and their ratings of managerial effectiveness. Therefore, consideration to subordinate ratings of expatriate performance is clearly warranted.

\section{Model for the current study}

Fig. 1 presents a model of the variables that were examined in the current study. The model shows that personal change and role innovation will have a direct impact on relations-oriented managerial practices. The managerial practices construct is represented by three conceptually distinct, though related behavioral practices: inspiring, supporting, and team building. These relations-oriented behaviors were selected for two reasons. First, they appear to be particularly relevant to the learning process that is associated with work role transitions. One of the core elements of the socialization process, which serves as the conceptual founding for Nicholson's (1984) work role transition theory, involves learning about interpersonal relationships (e.g., Chao et al., 1997). If personal changes and role innovations are intended to create alignment with others in the workplace, then these modes of adjustment should be linked to behaviors that are designed to facilitate effective work relationships. Second, these three managerial practices are consistent with several defining elements of the charismatic/value-based and team-oriented leadership dimensions which were found to have a high degree of cultural generalizability (House et al., 2004). As such, these relations-oriented practices may have utility across a wide range of cultural 
contexts. Therefore, Hypotheses $1 \mathrm{a}$ and $1 \mathrm{~b}$ are as follows:

H1a. Expatriate personal change will be significantly related to inspiring, supporting, and team building behaviors.

H1b. Expatriate role innovation will be significantly related to inspiring, supporting, and team building behaviors.

The model also shows that the relations-oriented behaviors will be related to two measures of contextual performance: subordinate ratings of managerial effectiveness and subordinate ratings of satisfaction with the expatriate manager. As noted above, previous research has demonstrated a link between relations-oriented managerial practices and these two types of outcome measures (Yukl et al, 1990). In addition, Caligiuri (1997) argued that managerial positions may involve a high degree of contextual performance demands. Thus, these measures may be among the most relevant "success" criteria. And finally, the use of subordinate ratings provides a fairly objective and accurate means for assessing contextual performance due to the comparatively high degree of regular and frequent contact with the expatriate manager. Therefore, Hypotheses $2 \mathrm{a}$ and $2 \mathrm{~b}$ are as follows:

H2a. Inspiring, supporting, and team building behaviors will be positively related to subordinate ratings of expatriate managerial effectiveness.

H2b. Inspiring, supporting, and team building behaviors will be positively related to subordinate ratings of satisfaction with their supervisor.

And finally, we considered the influence of several control variables that have been used in previous expatriate research and may have some influence on expatriate adjustment. Specifically, we accounted for the effects of education, marital status, number of children, tenure with current organization, tenure in current position, total years of work experience, age, selfreport regarding language fluency, and “cultural toughness” (e.g., Caligiuri et al., 1998; Takeuchi et al., 2002).

\section{Summary}

Based on Nicholson's (1984) work role transition theory and the research on leadership and managerial practices, we developed a model which links modes of adjustment, relations-oriented 
managerial behaviors, and contextual performance. Our analysis of this model extends previous research (e.g., Shay and Baack, 2004) by examining a more detailed and behavioral explanation of expatriate adjustment and the impact on key outcome variables. Specifically, we consider how expatriates adjust (i.e., modes of adjustment), as well as specific behaviors they may use during the adjustment process, that may mediate the adjustment-performance. Thus, the key contribution of the current study is the inclusion of relations-oriented managerial practices in the adjustmentperformance linkage. In addition, rather than relying on self-ratings of expatriate effectiveness which have been used in previous research on modes of adjustment (e.g., Shay and Baack, 2004), we used subordinate ratings of performance. This line of inquiry not only provides a means for validating previous work in this area, but also provides a more comprehensive and robust assessment of the modes of adjustment-performance relationship.

\section{Methods}

\section{Sample}

The data for this study were gathered from expatriate managers and their local national subordinates from several multinational hotel companies. At the time of this study, the American Hotel and Model Association Directory noted that there were 27 firms which manage three or more hotel properties overseas. Of these, nine agreed to participate in this study and provided complete data.

The two instruments used in the present study (i.e., expatriate general manager survey and local national subordinate survey) were field tested with corporate executives from nonparticipating firms, industry experts (faculty), and graduate students from a large private northeastern university. Feedback from pilot testing was used to make minor modifications to the instruments after which the instruments were again pilot tested with the ten different international graduate students to ensure that items had been clarified appropriately. Corporate contacts indicated that expatriate managers and functional level managers (i.e., subordinates) had a working knowledge of both written and spoken English, thereby supporting the use of English-only instruments.

Based on Latham and Wexley's (1994) suggestions, potential respondents were identified 
and selected on a systematic basis. For the expatriate sample, we controlled for confounds that may be due to differences across industry and position. Thus, the expatriate group included only the hotel general managers. For the local national subordinate sample, we selected only those individuals who had the most direct and frequent contact with the general manager. Thus, the subordinate group included those who held executive committee positions: controller, front office manager, human resources manager, and marketing director.

Surveys were sent to 310 expatriate general managers and 1240 subordinates. Two hundred twenty four surveys were returned by the general manager sample; 666 surveys were returned by the subordinate sample ( $72 \%$ and 54\% response rate, respectively). It should be noted that not all the subordinates were local nationals (i.e., some were expatriates). In order to be included in the sample for the current study, complete data from one expatriate manager and at least one subordinate were required. The final sample included responses from 194 expatriate hotel general managers and 505 subordinates. The expatriate general managers represented 32 different nationalities and were working in 83 different countries. One hundred eighty seven were male. The average age was approximately 47 years and they had worked an average of 12 years with their company. The subordinate sample represented 77 different countries. Three hundred thirty were male. The average age was approximately 38 years and they had worked an average of just over six years with their company. The number of subordinates for each expatriate ranged from one to four, with an average of 2.3 subordinate responses per expatriate general manager.

Based on Rousseau's (1985) suggestions, we examined this multi-level data set at the lowest level of analysis possible. Thus, the subordinate level of analysis (i.e., $N=505$ managersubordinate dyads) was used in order to preserve the variance among variables at different levels of analysis and ensure that the richness of the subordinate-level variance would not be reduced or lost by using alternative structuring procedures (e.g., aggregating the subordinate-level data at the expatriate manager level of analysis). This approach to analyzing the data is consistent with previous expatriate research (e.g., Shay and Baack, 2004), as well as dyadic analytic techniques that are used within the broader leadership research domain (e.g., Pillai and Meindl, 1999; Yammario and Dansereau, 2002).

\section{Procedures}


Using contact lists provided by the sponsoring organizations, the expatriate general managers received the following information via mail: one expatriate general manager survey, four surveys in sealed envelopes addressed to each of the general manager's four executive committee subordinates, instructions for distributing the subordinate surveys, and a letter from the principal researcher and an official from the expatriate's corporate headquarters asking for their assistance with this study and a guarantee of response confidentiality. The expatriate general managers were instructed to distribute the sealed envelopes directly to the executive committee subordinates. The sealed envelopes that were addressed to the subordinates included a survey and letter from the principal researcher and corporate contact encouraging their assistance with the project and assurance of confidentiality.

Follow-up letters were sent to the expatriate general managers two, four, and nine weeks after the initial mailing. We were given assurances by officials from the corporate headquarters of the sponsoring organizations that all respondents possessed a working knowledge of written and spoken English, thereby requiring only English-only surveys. Completed surveys were returned directly to the principal researcher via mail or fax to further ensure confidentiality.

\section{Measures}

\section{Expatriate personal change.}

West et al. (1987) four-item scale was used to assess expatriate self-reports of the degree to which the respondent engaged in personal change behaviors. Respondents were asked to indicate the extent to which adjusting to their new position had changed them in specific ways (i.e., values, attitudes, career goals, personality). A sample item of one specific way in which an expatriate may have changed was, "Values — what is important to me in life". Response choices ranged from 1 (Not at all) to 5 (A great extent).

\section{Expatriate role innovation.}

Black's (1992) six-item scale was used to assess expatriate self-reports of the degree to which respondents engaged in role innovation. Modifications were made to items to reflect the industry-specific nature of the study. Respondents were given the following instructions, "Think about what your position was like when you first arrived at this hotel compared to what your 
position is like right now. Reflecting on any changes that might have taken place, CIRCLE the extent to which you agree/disagree with the following statements". A sample statement was, "I have made significant changes in the nature of my job at this hotel (e.g., how I do my job)”. Response choices ranged from 1 (Strongly disagree) to 5 (Strongly agree).

\section{Managerial practices.}

Three scales from Yukl et al. (1990) Managerial Practices Survey (MPS) were used to assess three related but distinct relations- oriented behaviors: inspiring, supporting, and teambuilding. Each scale included four to six items which asked the local national subordinates to indicate the extent to which the expatriate general manager demonstrates the behavior described. An example item from the inspiring scale was, "develops enthusiasm for a task or project by appealing to pride in accomplishing a challenging task, beating competitors, or doing something never done before"; an example from the supporting scale was, "offers to provide advice or assistance when I need help with a difficult task or problem”; an example from the team building scale was, "encourages cooperation and teamwork among people who depend on each other to get the work done.” The response choices ranged from 1 (never, not at all) to 4 (usually, to a great extent).

Expatriate contextual performance (i.e., how well is the expatriate performing in a particular environment). Two measures were used to assess contextual performance. The first measure was Tsui's (1984) seven-item scale which assesses subordinate perceptions of expatriate managerial effectiveness. An example item was, "My general manager is widely recognized as a star (a very good manager).” Response choice alternative ranged from 1 (strongly disagree) to 5 (strongly agree). The second measure was Hackman and Oldham's (1980) three-item scale which assesses subordinate satisfaction with their supervisors. An example item was, "The degree of respect and fair treatment you receive from your general manager.” Response choice alternatives ranged from 1 (very dissatisfied) to 7 (very satisfied).

\section{Analyses}

First, we computed descriptive statistics and internal consistency reliability estimates for each of the measures. Then, we conducted correlation and regression analyses to test the 
mediational propositions. Following the procedures offered by Baron and Kenny (1986), James and Brett (1984), and others, we first assessed the extent to which the antecedent variables (expatriate modes of adjustment) were related to the criteria variables (subordinate ratings of expatriate effectiveness and supervisor satisfaction) (i.e., $X \rightarrow Y$ ). Then, we assessed the extent to which the antecedent variables were related to the mediators (relations- oriented managerial practices) (i.e., $X \rightarrow \mathrm{M}$ ). Next, we assessed the extent to which the mediator variables were related to the criteria (i.e., $M \rightarrow Y$ ). Finally, we assessed the extent to which the antecedent variables added explanatory variance in the $M \rightarrow Y$ equation. If adding the $X$ variables to the $M \rightarrow Y$ equation account for significant additional variance, and the beta weights for the $X$ and $M$ variables are significant in the final equation, then inferences of partial mediation can be made. If adding the $X$ variables to the $M \rightarrow Y$ equation account for significant additional variance, and the beta weights for $X$ are nonsignificant but the beta weights for the $M$ variables are significant in the final equation, then inferences of full mediation can be made.

\section{Results}

Table 1 presents the means, standard deviations, and internal consistency estimates (Cronbach's alpha) and bivariate correlations for all variables. All variables demonstrated adequate internal consistency reliabilities, ranging from 0.77 to 0.92 .

The results show that role innovation was significantly correlated with both contextual performance criteria (.13 with ratings of effectiveness, and .10 with satisfaction; $p<.01$ and $p<.05$, respectively). Similar results were found for the relationship between personal change and the performance measures (.14 with ratings of effectiveness, and .08 with satisfaction; $p<.01$ and $p<.05$, respectively). Expatriate role innovation was significantly related to each of the relationsoriented managerial practices scales (correlations ranged from .10 to .16; $p<.05$ or $p<.01$ ); however, personal change was not significantly related to any of the managerial practices dimensions. And finally, all three relations-oriented managerial practices were significantly related to the performance criteria (correlations ranged from .58 to .69, $p<.01$ ). Therefore, the first three conditions were satisfied for establishing support for the proposed mediational effects of the relations-oriented managerial practices in the role innovation- contextual performance relationship. 
To test the fourth and final requirement for establishing inferences regarding mediation, a series of hierarchical regression analyses was conducted. Given the non-significant relationships between personal change and the three relations-oriented managerial practices, only role innovation was examined. Separate analyses were conducted for each of the criterion variables. The control variables were entered first, followed by scale scores for the three relations-oriented managerial practices, and then scale scores for role innovation. For subordinate ratings of expatriate managerial effectiveness, only the three managerial practices had significant beta weights in the final equation ( 0.47 for inspiring, 0.13 for supporting, and .18 for team building; overall R- square $=0.52, F=44.16, \mathrm{df}=494)$. Similarly, for subordinate ratings of supervisor satisfaction, only the three relations-oriented managerial practices had significant beta weights in the final equation (0.34 for inspiring, 0.24 for supporting, and 0.26 for team building; overall Rsquare $=0.56, F=50.25, \mathrm{df}=494)$. Therefore, these findings support inferences of full mediation for relations- oriented managerial practices in the role innovation-contextual performance relationship. Tables 2 and 3 present the overall results from the regression analyses.

On a final note, given the moderately high correlations among the relations-oriented managerial practices, we examined the variance inflation factor (VIF) values from the regression analyses to determine if there may be concerns regarding multicollinearity. VIF measures identify the degree to which each independent variable may be explained by other independent variables. A common cutoff threshold corresponds to a VIF value above 10 (Hair et al., 1998). The highest VIF value was 4.10 , which suggests that multicollinearity was not a concern.

\section{Discussion}

Due to the high costs of sending expatriates overseas and the critical role that they play in overseas subsidiaries, multinational firms have become increasingly interested not only in whether the expatriates are adjusted, but also whether they succeed in meeting the firm's goals for the assignment. The current study demonstrates the importance of examining the specific behaviors that expatriate managers may use to achieve their objectives. While a few studies have demonstrated positive relationships between modes of adjustment and expatriate managerial

performance (e.g., Shay and Baack, 2004), this research has not fully explicated the process and outcomes of adjustment. By examining the specific behaviors that expatriates may use during their 
adjustment process, our results build on Nicholson's (1984) work role transition theory and provide a more behaviorally-based explanation about how expatriate managers may become adjusted to their overseas assignments, influence those with whom they work, and fulfill their role responsibilities. Our results indicate that inspiring, supporting, and team building behaviors appear to mediate the role of innovation-contextual performance relationship. Thus, expatriates who assume a more externally-oriented approach to change during the adjustment process may enhance their performance by engaging in these relations-oriented behaviors.

We were a bit surprised that no significant results were found for the relationships between personal change and the three relations-oriented managerial practices. One explanation is that internally-oriented change efforts are not as explicit as role innovation efforts. So although an expatriate manager may actually change his or her values and attitudes, which may ultimately influence his/her contextual performance (indicated by the significant though not very strong relationships between personal change and the two outcome measures), such change may not be as visible to his or her subordinates. Moreover, Liu and Shaffer (2005) found significant relationships between opportunity forms of social capital (i.e., host country national network density and depth of relationship) and ability forms of social capital (i.e., host country national cultural empathy) and expatriate job performance. Thus, the personal change-contextual performance relationship may be mediated to variables such as included social capital explanations that were not considered in the current study.

Another important finding from this study was the support for the cultural generalizability of relations-oriented managerial practices. While it is clear that some leadership and managerial behaviors may have limited utility across cultural settings (e.g., House et al., 1997), those that are associated with charismatic/value-based and team-oriented leadership dimensions appear to be much more applicable across a wide array of cultural contexts. Managing others is a key responsibility for many expatriates (Tung, 1982). As such, models that explain the adjustmentperformance relationship should include the mediating effects of recognizing, supporting, and team building practices, as well as other relations-oriented managerial behaviors that may have broad cultural relevance.

The current findings also offer prescriptive guidance for improving expatriate adjustment and performance. For example, it may be beneficial to implement formal pre-assignment training 
programs that focus on developing an expatriate's relations- oriented behaviors. Efforts to develop these behaviors may help expatriates work more effectively with their subordinates and colleagues, and thereby facilitate a smoother transition to their overseas assignment. In addition, coaching efforts (by an expatriate's supervisor) which emphasize the use of inspiring, supporting, and team building may help expatriates build their confidence and become better-adjusted during the initial stages of their assignment, and thus, be more likely to achieve desired performance results. And finally, the expatriate performance evaluation process may be enhanced considerably by incorporating detail regarding the use and effectiveness of the focal managerial behaviors. A more comprehensive assessment process that includes information about relations-oriented practices may help identify the behaviors that facilitate a more productive work environment, and ultimately lead to desired performance goals.

We should note that there may be other types of managerial practices that provide a means for elaborating on the links between modes of adjustment and measures of expatriate performance. As noted above, Nicholson's (1984) theory is based in part on the socialization research, which has identified several types of learning that may be evident when an individual enters a new organizational context. In addition to learning about how to interact effectively with those in one's immediate work context, another key learning dimension focuses on the tasks, duties, and responsibilities that are specific to one's job (Chao et al., 1997). Thus, efforts to effectively “redesign situational demands" (Nicholson, 1984, p. 173) and manipulate the environment to create person-context alignment (i.e., role innovation) may require other types of managerial practices, such as communication and planning. For example, Leung et al. (2001) single host country study (expatriates working in China) found significant relationships between planning and participative management behaviors and important outcomes such as general satisfaction, organizational commitment, and satisfaction towards expatriate manager. As such, these behaviors, which may be part of the culturally-generalizable leadership domain, should also be considered in future model development and in studies which extend beyond a single country.

And finally, this study highlights the importance of using independent sources of contextual performance data. Much of the previous research suffers from measurement bias or has utilized data from individuals who may not be appropriate for making such evaluations. Many studies have used self-report ratings of performance and effectiveness (e.g., Parker and McEvoy, 1993; Caligiuri, 1997), which introduces the likelihood of same source bias and may artificially 
inflate or distort the magnitude of the observed relationship (Fiske, 1982). Others have utilized data from supervisors who do not have the regular and frequent opportunities to make performance observations. Local national subordinates provide an important source of performance data because they have the opportunity to observe expatriates directly and understand which behaviors are important to succeed. Moreover, the quality of relationships among expatriates and local nationals is critical to the successful operation of the overseas subsidiary. Thus, we concur with Caligiuri's (1997) suggestion to consider multiple sources of performance data as a means for reducing bias and increasing the validity of future adjustment research.

\section{Limitations and suggestions for future research}

There are several limitations of this study that, in addition to the issues noted above, offer direction for future research. Some of the limitations of this research are consistent with those noted in prior empirical studies conducted in this field. Given that we did not collect our data over time, the cross-sectional nature of the design limits us from making definitive causal statements. Regardless of this concern, we can conclude that the data appear to support the theoretical arguments that we outlined, and the use of longitudinal studies can be used to confirm our findings.

All the data for the current study were collected via questionnaire. Thus, any observed relations might be due in part to common method effects (Fiske, 1982). However, we did attempt to attenuate its effect by collecting our data from multiple sources (cf., Podsakoff and Organ, 1986). We note, though, that some of the observed relationships were between those constructs that were reported by the same group of respondents, which in itself might indicate the influence of common method effects. However, unlike most of the extant expatriate research, the present study utilized data from local national subordinates who are arguably in the best position to make the type of regular and frequent observations of expatriate behaviors and effectiveness necessary to make accurate organizational assessments of the expatriates' performance on the job.

Since our data were collected from a single industry, there may be concerns regarding the generalizability of our findings to other settings. However, the structure of the hotel industry provides an excellent opportunity to conduct international human resources research. For example, the multinational companies included in our sample had at least three subsidiary hotels outside the country in which the parent company was located. Moreover, each of these multinationals 
maintained similar managerial structures (i.e., each subsidiary hotel employed only one expatriate general manager and similar sets of subordinate functional level managers), which reduced the potential for introducing extraneous noise into the research design. Regardless of these arguments, replications of the current study using cross-industry samples are recommended.

Finally, we recognize that we did not control for several variables that have previously been associated with expatriate adjustment (e.g., cross-cultural training, readiness, and preparation: Black and Mendenhall, 1990; spousal support, parent company support, and local subsidiary support: Kraimer et al., 2001). Moreover, none of the controls included in the current study contributed any explanatory power to the proposed relationships. Future studies should consider the possibility that variables shown to influence the expatriate adjustment process may influence the relationship between modes of adjustment and contextual performance. 


\section{References}

Baron, R.M., Kenny, D.A., 1986. The moderator-mediator variable distinction in social psychological research: conceptual, strategic, and statistical considerations. Journal of Personality and Social Psychology 51, 1173-1182.

Barrett, R.S., 1966. The influence of the supervisor's requirements on ratings. Personnel Psychology 19, 375-387.

Bass, B.M., 1990. Handbook of Leadership: A Survey of Theory and Research. Free Press, New York, NY.

Bhaskar-Shrinivas, P., Harrison, D., Shaffer, M.A., Luk, D.M., 2005. Input-based and time-based models of international adjustment: meta-analytic evidence and theoretical extensions. Academy of Management Journal 48 (2), 257-280.

Black, J.S., 1988. Work role transitions: a study of American expatriate managers in Japan. Journal of International Business Studies 19, 277-294.

Black, J.S., 1992. Socializing American expatriate managers overseas. Group and Organization Management 17, 171-192.

Black, J.S., Gregersen, H.B., 1991. Antecedents to cross-cultural adjustment for expatriates in Pacific Rim assignments. Human Relations 44, 497-515.

Black, J.S., Gregersen, H.B., 1999. The Right Way to Manage Expats. Harvard Business Review, pp. 52-62. March-April.

Black, J.S., Mendenhall, M., 1990. Cross-cultural training effectiveness: a review and a theoretical framework for future research. Academy of Management Review 15, 113-136.

Black, J.S., Mendenhall, M., Oddou, G., 1991. Toward a comprehensive model of international adjustment: an integration of multiple theoretical perspectives. Academy of Management Review 16, 291-317.

Caligiuri, P.M., 1997. Assessing Expatriate Success: Beyond Just “Being There.”. In: Saunders, D.M., Aycan, Z. (Eds.), New Approaches to Employment Management. JA1 Press, Greenwich, CT, pp. 117-140.

Caligiuri, P.B., 2000. The Big Five personality characteristics as predictors of expatriates' desire 
to terminate the assignment and supervisor-rated performance. Personnel Psychology 53, 67-88.

Caligiuri, P.B., Hyland, M.M., Joshi, A., Bross, A.S., 1998. Testing a theoretical model for examining the relationship between family adjustment and expatriates' work adjustment. Journal of Applied Psychology 83, 598-613.

Chao, G.T., O'Leary-Kelly, A.M., Wolf, S., Klein, H.J., Garnder, P.D., 1997. Organizational socialization: its content and consequences. Journal of Applied Psychology 79, 730-743.

Copeland, L., Griggs, L., 1985. Going International. Random House, New York, NY.

Dorfman, P.W., 2004. International and Cross-cultural Leadership Research, In: Punnett, B.J., Shenkar, O. (Eds.), Handbook for International Management Research, 2nd Edition. University of Michigan Press, Ann Arbor, MI, pp. 267-349.

Fiske, D., 1982. Convergent-discriminant Validation in Measurements and Research Strategy. In: Brinsberg, D., Kidder, L. (Eds.), New Directions for Methodology of Social and Behavioral Science: Forms of Validity in Research. Jossey-Bass, San Francisco, CA, pp. 77-92.

Gregersen, H.B., Black, J.S., 1990. A multifaceted approach to retention in international assignments. Group and Organization Studies 15, 461-485.

Gregersen, H.B., Hite, J.M., Black, J.S., 1996. Expatriate performance appraisal in U.S. multinational firms. Journal of International Business Studies 27, 711-738.

Hackman, J.R., Oldham, G.R., 1980. Work Redesign. Addison-Wesley, Reading, MA.

Hair, J.F., Anderson, R.E., Tatham, R.L., Black, W.C., 1998. Multivariate Data Analysis, 5th Edition. Prentice-Hall, Englewood Cliffs, NJ.

Hanges, P.J., Dickson, M.W., 2004. The Development and Validation of the GLOBE Culture and Leadership Scales. In: House, R.J., Hanges, P.J., Javidan, M., Dorfman, P.W., Gupta, V. (Eds.), Culture, Leadership, and Organzations: The GLOBE Study of 62 Societies. Sage Publications, Thousand Oaks, CA, pp. 122-151.

Hannigan, T.P., 1990. Traits, attitudes, and skills that are related to intercultural effectiveness and their implications for cross-cultural training: a review of the literature. International Journal of Intercultural Relations 14, 89-111. 
Hemphill, J.K., 1949. The leader and his group. Journal of Educational Research 28 (225-229), 245-246.

Hofstede, G., 1980. Cultures Consequences: International Differences in Work-Related Values. Sage, Beverly Hills, CA.

Holzbach, R., 1978. Rater bias in performance rating: supervisor, self, and peer ratings. Journal of Applied Psychology 63, 579-588.

House, R.J., Mitchell, T.R., 1974. Path-goal theory of leadership. Contemporary Business 3, 8198.

House, R.J., Wright, N.S., Aditya, R.N., 1997. Cross-cultural Research on Organizational Leadership: A Critical Analysis and a Proposed Theory. In: Early, P.C., Erez, M. (Eds.), New Perspectives in International Industrial Organizational Psychology. New Lexington, San Francisco, CA, pp. 535-625.

House, R.J., Hanges, P.J., Javidan, M., Dorfman, P.W., Gupta, V., 2004. Culture, Leadership, and Organizations: The GLOBE Study of 62 Societies. Sage Publications, Thousand Oaks, CA.

James, L.R., Brett, J.M., 1984. Mediators, moderators, and tests for mediation. Journal of Applied Psychology 69, 307-321.

Jones, E.E., Davis, K.E., 1965. From acts to Dispositions: The Attribution Process in Person Perception. In: Berkowitz, L. (Ed.), Advances in Experimental Social Psychology, pp. 151174.

Katz, D., Kahn, R.L., 1952. Some Recent Findings in Human Relations Research. In: Swanson, E., Newcomb, T., Hartley, E. (Eds.), Readings in Social Psychology. Holt, New York, NY.

Katz, D., Maccoby, N., Morse, N., 1950. Productivity, Supervision, and Morale in an Office Situation. Institute for Social Research, Ann Arbor, MI.

Katz, D., Maccoby, N., Gurin, G., Floor, L., 1951. Productivity, Supervision, and Morale Among Railroad Workers. Survey Research Center, University of Michigan, Ann Arbor, MI.

Kraimer, M.L., Wayne, S.J., Jaworski, R.A., 2001. Sources of support and expatriate performance: the mediating role of expatriate adjustment. Personnel Psychology 54, 71-99.

Latham, G.P., Wexley, K.N., 1994. Increasing Productivity Through Performance Appraisal, 2nd 
Edition. Addison-Wesley Publishing Company, Reading, MA.

Leung, K., Wang, Z., Smith, P.B., 2001. Job attitudes and organizational justice in joint venture hotels in China: the role of expatriate managers. International Journal of Human Resource Management 12 (6), 926-945.

Liu, X., Shaffer, M.A., 2005. An investigation of expatriate adjustment and performance: a social capital perspective. International Journal of Cross-cultural Management 5 (3), 235-254.

Luthans, F., Lockwood, D.L., 1984. Toward an Observation System for Measuring Leader Behavior in Natural Settings. In: Hunt, J.G., Hosking, D., Schriesheim, C.A., Stewart, R. (Eds.), Leaders and Managers: International Perspectives on Managerial Behavior and Leadership. Pergamon Press, New York, pp. 117-141.

Meyer, H., 1980. Self-appraisal of job performance. Personnel Psychology 33, 291-295.

Mintzberg, H., 1973. The Nature of Managerial Work. Harper \& Row, New York.

Morse, J.J., Wagner, F.R., 1978. Measuring the process of managerial effectiveness. Academy of Management Journal 21, 23-35.

Nicholson, N., 1984. A theory of work role transitions. Administrative Science Quarterly 29, 172191.

Parker, B., McEvoy, G., 1993. Initial examination of a model of intercultural adjustment. International Journal of Intercultural Relations 17, 355-381.

Pillai, R., Meindl, J.R., 1999. Context and charisma: a “meso” level examination of the relationship of organic structure, collectivism, and crisis to charismatic leadership. Journal of Management 24, 643-663.

Podsakoff, P.M., Organ, D.W., 1986. Self-reports in organizational research: problems and prospects. Journal of Management 12, 531-544.

Rousseau, D.M., 1985. Issues of Level in Organizational Research: Multi-level and Cross-level Perspectives. In: Cummings, L.L., Staw, B.M. (Eds.), Research in Organizational Behavior. JAI Press, Greenwich, CT, pp. 1-37.

Shay, J.P., Baack, S., 2004. Expatriate assignment, adjustment and effectiveness: an empirical examination of the big picture. Journal of International Business Studies 35, 216-232. 
Stogdill, R.M., 1974. Handbook of Leadership: A Survey of the Literature. Free Press, New York.

Takeuchi, R., Yu, S., Russell, J.E.A., 2002. Antecedents and consequences of the perceived adjustment of Japanese expatriates in the USA. International Journal of Human Resource Management 13, 1224-1244.

Takeuchi, R., Marinova, S.V., Lepak, D.P., Liu, W., 2005a. A model of expatriate withdrawalrelated outcomes: decision making from a dualistic adjustment perspective. Human Resource Management Review 15, 119-138.

Takeuchi, R., Tesluk, P.E., Yun, S., Lepak, D.P., 2005b. An integrative view of international experience. Academy of Management Journal 48 (1), 85-100.

Takeuchi, R., Wang, M., Marinova, S.V., 2005c. Antecendents and consequences of psychological workplace strain during expatriation: a cross-sectional and longitudinal investigation. Personnel Psychology 58, 925-948.

Thomas, D.C., Ravlin, E.C., 1995. Responses of employees to cultural adaptation by a foreign manager. Journal of Applied Psychology 80, 133-146.

Thomas, D.C., Toyne, B., 1995. Subordinates' responses to cultural adaptation by Japanese expatriate managers. Journal of Business Research 32, 1-10.

Thornton, G., 1980. Psychometric properties of self-appraisal and job performance. Personnel Psychology 33, 263-271.

Triandis, H.C., 1994. Culture and Social Behavior. McGraw-Hill, New York, NY.

Tsui, A.S., 1984. A role-set analysis of managerial reputation. Organizational Behaviour and Human Performance 34, 64-96.

Tung, R.L., 1981. Selecting and training of personnel for overseas assignments. Columbia Journal of World Business 16, 68-78.

Tung, R.L., 1982. Selection and training procedures of U.S., European, and Japanese multinationals. California Management Review 25, 57-71.

Van Mannen, J., Schein, E., 1979. Toward a Theory of Organizational Socialization. In: Staw, B. (Ed.), Research in Organizational Behavior. JAI Press, Greenwich, CT, pp. 209-264. 
West, M.A., 1987. Role innovation in the world of work. British Journal of Social Psychology 26, 305-315.

West, M.A., Rushton, R., 1989. Mismatches in the work-role transition. Journal of Occupational Psychology 62, 271-286.

West, M.A., Nicholson, N., Rees, A., 1987. Transitions into newly created jobs. Journal of Occupational Psychology 60, 97-113.

Yammario, F.J., Dansereau, F., 2002. Individualized transition. Journal of Leadership and Organization Studies 9, 90-99.

Yukl, G., 1990. COMPASS: The Managerial Practices Survey. Gary Yukl and Manus Associates, New York.

Yukl, G., 2002. Leadership in Organizations, 5th Edition. Prentice Hall, Englewood Cliffs, NJ.

Yukl, G., Wall, S., Lepsinger, R., 1990. Preliminary Report on Validation of The Managerial Practices Survey. In: Clark, K.E., Clark, M.B. (Eds.), Measures of Leadership. Leadership Library of America, West Orange, NJ. 
Table 1. Means, standard deviations, correlations, and internal consistency estimates.

\begin{tabular}{|c|c|c|c|c|c|c|c|c|c|}
\hline & Mean & Std dev & RI & PC & Insp & Sup & TB & Eff & Sat \\
\hline E - role innovation $(\mathrm{RI})$ & 3.15 & 0.53 & $(0.77)$ & & & & & & \\
\hline $\mathrm{E}$ - personal change (PC) & 3.17 & 0.84 & $0.46^{* *}$ & $(0.90)$ & & & & & \\
\hline $\mathrm{S}$ - inspiring (Insp) & 4.10 & 0.76 & $0.12^{*}$ & 0.04 & $(0.86)$ & & & & \\
\hline S - supporting (Sup) & 4.10 & 0.91 & $0.10^{* *}$ & 0.02 & $0.66^{* *}$ & $(0.88)$ & & & \\
\hline $\mathrm{S}$ - team building (TB) & 4.15 & 0.82 & $0.16 * *$ & 0.05 & $0.70 * *$ & $0.74 * *$ & $(0.88)$ & & \\
\hline $\begin{array}{l}S \text { - ratings of expatriate } \\
\text { effectiveness (Eff) }\end{array}$ & 3.52 & 0.89 & $0.13^{*}$ & $0.14^{* *}$ & $0.69 * *$ & $0.58 * *$ & $0.62 * *$ & $(0.80)$ & \\
\hline $\begin{array}{l}\mathrm{S} \text { - ratings of supervisor } \\
\text { satisfaction (Sat) }\end{array}$ & 5.28 & 1.44 & $0.10^{* *}$ & $0.08^{*}$ & $0.67^{* *}$ & $0.65 * *$ & $0.67 * *$ & $0.75^{* *}$ & $(0.92)$ \\
\hline
\end{tabular}

$N=505$.

Scale reliabilities appear within parentheses.

${ }^{*} p<.05, * * p<.01$ (one-tailed).

$\mathrm{E}=$ expatriate respondents.

$\mathrm{S}=$ subordinate respondents 
Table 2. Regression results for ratings of expatriate effectiveness.

\begin{tabular}{|c|c|c|c|c|c|c|}
\hline \multirow[t]{2}{*}{ Step } & & \multicolumn{2}{|c|}{$\underline{\text { Unstandardized coefficients }}$} & \multirow{2}{*}{$\begin{array}{l}\text { Standardized coefficients } \\
\text { Beta }\end{array}$} & \multirow[t]{2}{*}{$t$} & \multirow[t]{2}{*}{ Sig. } \\
\hline & & $\beta$ & $\overline{\text { Std. error }}$ & & & \\
\hline \multirow[t]{9}{*}{1} & (Constant) & 4.220 . & 449 & 9.389 & .000 & \\
\hline & A: years of education & -.061 & .026 & -.116 & -2.376 & .018 \\
\hline & B: marital status & -.061 & .085 & -.035 & -.721 & .471 \\
\hline & C: number of children & .056 & 043 & .065 & 1.290 & .198 \\
\hline & D: tenure—current org. & .012 & .005 & .100 & 2.131 & .034 \\
\hline & E: tenure-current job & .016 & .011 & .131 & 1.494 & .136 \\
\hline & F: age & -.020 & .012 & -.150 & -1.692 & .091 \\
\hline & G: language fluency & -.049 & .025 & -.088 & -1.926 & .055 \\
\hline & H: cultural toughness & .029 & .046 & .029 & .642 & .521 \\
\hline \multirow[t]{12}{*}{2} & (Constant) & -.287 & $.379-$ & .758 & .449 & \\
\hline & A & -.006 & .018 & -.012 & -.337 & .736 \\
\hline & B & -.014 & .060 & -.008 & -.231 & .817 \\
\hline & $\mathrm{C}$ & .015 & .031 & .017 & .482 & .630 \\
\hline & $\mathrm{D}$ & .006 & .004 & .053 & 1.588 & .113 \\
\hline & $\mathrm{E}$ & -.001 & .008 & -.009 & -.151 & .880 \\
\hline & $\mathrm{F}$ & .003 & .008 & .021 & .336 & .737 \\
\hline & G & -.009 & .018 & -.017 & -.516 & .606 \\
\hline & $\mathrm{H}$ & .038 & .033 & .037 & 1.153 & .250 \\
\hline & Inspiring & .553 & .055 & .471 & 10.143 & .000 \\
\hline & Supporting & .122 & .048 & .125 & 2.539 & .011 \\
\hline & Team building & .201 & .057 & 185 & 3.509 & .000 \\
\hline \multirow[t]{13}{*}{3} & (Constant) & -.407 & .412 & -.988 & .324 & \\
\hline & A & -.006 & .018 & -.012 & -.350 & .726 \\
\hline & B & -.011 & .060 & -.007 & -.187 & .852 \\
\hline & $\mathrm{C}$ & .018 & .031 & .021 & .576 & .565 \\
\hline & $\mathrm{D}$ & .006 & .004 & .051 & 1.535 & .125 \\
\hline & $\mathrm{E}$ & -.001 & .008 & -.009 & -.137 & .891 \\
\hline & F & .002 & .008 & .018 & .287 & .775 \\
\hline & $\mathrm{G}$ & -.010 & .018 & -.018 & -.538 & .591 \\
\hline & $\mathrm{H}$ & .036 & .033 & .035 & 1.091 & .276 \\
\hline & Inspiring & .552 & .055 & .470 & 10.111 & .000 \\
\hline & Supporting & .123 & .048 & .126 & 2.565 & .011 \\
\hline & Team building & .196 & .058 & .180 & 3.402 & .001 \\
\hline & $\begin{array}{l}\text { Expatriate } \\
\text { innovation }\end{array}$ & .042 & .056 & .024 & .748 & .455 \\
\hline
\end{tabular}

Model summary:

Step 1: R-square change $=0.04(\mathrm{p}<.01) ; \mathrm{F}$ change $=2.83, \mathrm{df}=(8,486)$.

Step 2: R-square change $=0.48(\mathrm{p}<.01) ; \mathrm{F}$ change $=161.61, \mathrm{df}=(11,483)$.

Step 3: R-square change $=0.00$ (ns); F change $=0.56, \mathrm{df}=(12,482)$. 
Table 3. Regression results for ratings of satisfaction with supervisor.

\begin{tabular}{|c|c|c|c|c|c|c|}
\hline \multirow[t]{2}{*}{ Step } & & \multicolumn{2}{|c|}{$\underline{\text { Unstandardized coefficients }}$} & \multirow{2}{*}{$\frac{\text { Standardized coefficients }}{\text { Beta }}$} & \multirow[t]{2}{*}{$\mathrm{t}$} & \multirow[t]{2}{*}{ Sig. } \\
\hline & & $\mathrm{B}$ & $\overline{\text { Std. error }}$ & & & \\
\hline \multirow[t]{9}{*}{1} & (Constant) & 6.796 & .733 & 9.277 & .000 & \\
\hline & A: years of education & -.085 & .042 & -.100 & -2.034 & .042 \\
\hline & B: marital status & -.118 & .138 & -.042 & -.852 & .395 \\
\hline & C: number of children & .050 & .071 & .036 & .715 & .475 \\
\hline & $\begin{array}{l}\text { D: tenure-current } \\
\text { org. }\end{array}$ & .012 & .009 & .062 & 1.321 & .187 \\
\hline & $\begin{array}{l}\text { E: tenure-current } \\
\text { job }\end{array}$ & .028 & .018 & .139 & 1.571 & .117 \\
\hline & F: age & -.037 & .019 & -.172 & -1.921 & .055 \\
\hline & G: language fluency & -.083 & .041 & -.093 & -2.025 & .043 \\
\hline & H: cultural toughness & .004 & .075 & .002 & .050 & .960 \\
\hline \multirow[t]{12}{*}{2} & (Constant) & -.865 & .593 & -1.459 & .145 & \\
\hline & A & .009 & .029 & .011 & .317 & .751 \\
\hline & B & -.015 & .094 & -.006 & -.164 & .870 \\
\hline & $\mathrm{C}$ & -.028 & .048 & -.020 & -.578 & .563 \\
\hline & $\mathrm{D}$ & .002 & .006 & .012 & .368 & .713 \\
\hline & $\mathrm{E}$ & -.002 & .012 & -.008 & -.128 & .898 \\
\hline & F & .002 & .013 & .008 & .135 & .893 \\
\hline & $\mathrm{G}$ & -.006 & .028 & -.007 & -.208 & .836 \\
\hline & $\mathrm{H}$ & 020 & .051 & .012 & .393 & .695 \\
\hline & Inspiring & .643 & .085 & .339 & 7.546 & .000 \\
\hline & Supporting & .387 & .075 & .244 & 5.154 & .000 \\
\hline & Team building & .442 & .089 & .252 & 4.954 & .000 \\
\hline \multirow[t]{13}{*}{3} & (Constant) & -.676 & .643 & -1.050 & .294 & \\
\hline & A & .010 & .029 & .011 & .331 & .741 \\
\hline & B & -.020 & .094 & -.007 & -.207 & .836 \\
\hline & $\mathrm{C}$ & -.033 & .049 & -.024 & -.673 & .501 \\
\hline & $\mathrm{D}$ & .003 & .006 & .013 & .416 & .678 \\
\hline & $\mathrm{E}$ & -.002 & .012 & -.009 & -.142 & .887 \\
\hline & $\mathrm{F}$ & .002 & .013 & .011 & .183 & .855 \\
\hline & $\mathrm{G}$ & -.005 & .028 & -.006 & -.185 & .854 \\
\hline & $\mathrm{H}$ & .023 & .051 & .014 & .450 & .653 \\
\hline & Inspiring & .645 & .085 & .340 & 7.562 & .000 \\
\hline & Supporting & .385 & .075 & .243 & 5.119 & .000 \\
\hline & Team building & .450 & .090 & .256 & 5.005 & .000 \\
\hline & Role innovation & -.066 & .087 & -.024 & -.757 & .449 \\
\hline
\end{tabular}

Model summary:

Step 1: R-square change $=0.03$ (ns); F change $=1.93$, $\mathrm{df}=(8,486)$.

Step 2: R-square change $=0.53(\mathrm{p}<.01)$; $\mathrm{F}$ change $=189.86, \mathrm{df}=(11,483)$.

Step 3: R-square change $=0.00$ (ns); F change $=0.57, \mathrm{df}=(12,482)$. 


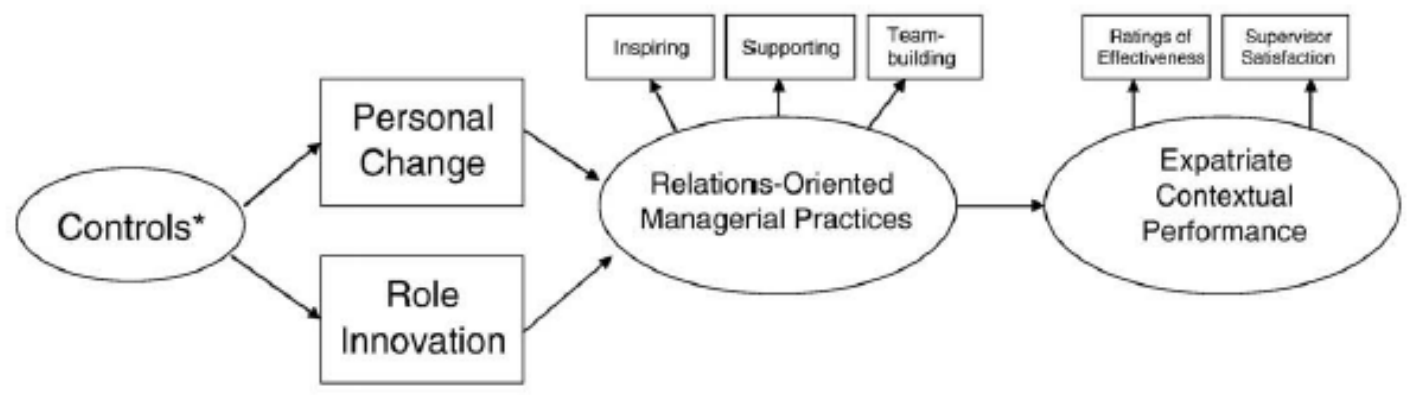

-Controls:

-Education

- Marital Status

- Number of Children

-Tenure-Current Organization

-Tenure-Current Job

-Age

-Language Fluency

-Cultural Toughness

Figure1. Conceptual model. 